\title{
Perceptions and Attitudes Towards Shoulder Padding and Shoulder Injury in Rugby Union
}

\author{
Angus Hughes $^{1}\left[\right.$ [D $\cdot$ Matt Carré ${ }^{1} \cdot$ Heather Driscoll ${ }^{2}$
}

Received: 12 January 2021 / Accepted: 15 September 2021 / Published online: 2 November 2021

(c) The Author(s) 2021

\begin{abstract}
Purpose To develop an understanding of the role of shoulder padding in rugby union by investigating player perceptions and attitudes towards shoulder padding and extending research into shoulder injuries in rugby.

Methods An online survey was distributed to past and current rugby players over 13 years old in 2018. Questions related to the participants' demographic, attitudes to shoulder padding and shoulder injury history.

Results Six hundred and sixteen rugby players responded to the survey; $66.1 \%$ of respondents had worn shoulder padding at some point. The age group 24-29 years old $\left(\Delta R^{2}=0.03, B=-0.53, P=0.015\right)$ had an inverse association with padding effectiveness while playing experience groups $1-2$ years $\left(\Delta R^{2}=0.03, B=0.8, P=0.032\right), 3-5$ years $\left(\Delta R^{2}=0.03, B=0.70\right.$, $P=0.002)$ and 6-9 years $\left(\Delta R^{2}=0.03, B=0.41, P=0\right)$ had a positive association. There are $37.1 \%$ of respondents considering shoulder padding to be effective at preventing cuts and abrasions with $21.9 \%$ finding it very effective; $50.3 \%$ considered it to be effective or very effective (9.7\%) at preventing contusion; $45.5 \%$ wore padding for injury prevention, while $19.2 \%$ wore padding to protect from reoccurring injury. Sprain/ligament damage (57.5\%) and bruising (55.5\%) were the most commonly reported injuries.

Conclusions The primary reason for wearing shoulder padding was as a means of injury prevention. Research should focus on quantifying the injury preventive capabilities of shoulder padding. Bruising, cuts and abrasion injuries to the shoulder are prevalent presenting new findings that these injuries are underreported.
\end{abstract}

Keywords Rugby union $\cdot$ Shoulder padding $\cdot$ Protective equipment $\cdot$ Epidemiology $\cdot$ Attitudes

\section{Introduction}

Rugby union is a collision sport, resulting in a relatively high injury rate of 90.1 per 1000 player match hours $(\mathrm{PMH})$ in elite rugby [7], this however is lower in the amateur game with 46.8 injuries per $1000 \mathrm{PMH}$ [21]. This can be compared with soccer (64.4 per $1000 \mathrm{PMH}$ ) and tennis (31.1 per 1000 $\mathrm{PMH)}$ [14]. On average, one rugby match leads to 456.8

Angus Hughes

angus.hughes@sheffield.ac.uk

Matt Carré

m.j.carre@sheffield.ac.uk

Heather Driscoll

h.driscoll@sheffield.ac.uk

1 Department of Mechanical Engineering, The University of Sheffield, Sheffield S10 2TN, UK

2 Advanced Manufacturing Research Centre, The University of Sheffield, Sheffield S60 5TZ, UK impacts [5], these impacts are mostly seen in the tackle (48\%). The $65 \%$ of shoulder injuries are caused in the tackle [11], therefore, although not as prevalent as lower limb injuries (50.6 per $1000 \mathrm{PMH} \mathrm{[7])} \mathrm{shoulder} \mathrm{injuries} \mathrm{have} \mathrm{a} \mathrm{sub-}$ stantial incidence rate in elite rugby union (12.7 per 1000 PMH [16]). This however, is far lower in the amateur game (3.1 per $1000 \mathrm{PMH}$ [21]). The epidemiology of shoulder injury in rugby union has been reported [16] with common injuries including acromioclavicular (ac) joint injury (3.7 per 1000 PMH), Dislocations (1.8 per 1000 PMH) and Hematomas/Bruising (2.1 per $1000 \mathrm{PMH}$ ). However, the definition of injury used in this research $(24+$ hour time loss from all participation) creates suspicion that less severe injuries including Bruising, Cuts and Abrasions are under reported.

Shoulder padding can be used by rugby players under their jersey. It possesses properties that allow it to dissipate a certain amount of impact energy resulting in it being reported that $70 \%$ of players will wear shoulder padding to reduce the risk of injury [13]. However, the ability of 
shoulder padding to reduce injury has not been quantitatively assessed, therefore should not be considered as a means of injury prevention. Coupled with this, regulations have been set by rugby's governing body World Rugby to control its impact protection potential by setting a maximum limit to its force attenuative properties [19], and as such World Rugby do not view shoulder padding as a form of significant protection, and is only intended to protect from Cuts and Abrasions [20].

Recent research has explored protective headwear in rugby union with $67 \%$ of rugby players having worn it [1]. However, players' attitudes towards the use of shoulder padding is generally un-researched, these attitudes can be defined as an athletes' opinion towards shoulder padding and can have an influential effect on the use of shoulder padding. Knowledge of perceptions and attitudes or actions towards shoulder padding should be established in order to understand the role of shoulder padding in injury prevention and to help develop new products and methodologies with which to assess their performance. These attitudes and behaviors can also vary between sub groups (i.e. gender, age and playing level), knowledge of this can inform commercial and manufacturing processes.

The study therefore, firstly aims to develop detailed knowledge of players' attitudes and perceptions of shoulder padding through a mixed methods design, while examining how different sub groups may differ in their perceptions and attitudes. Secondly, the study aims to examine shoulder injury epidemiology of rugby players, including any effects of players' attitudes and perceptions of shoulder padding.

\section{Methods}

\section{Survey Development}

After institutional ethical approval an online survey was developed. During the preparation of this study, 25 rugby players contributed to the development of the survey through commenting on an initial set of pilot questions. After evaluation of this pilot via interview with pilot testers, a final questionnaire was presented as an online survey using Google Forms.

Section 1 of the survey collected demographic and playing information. Section 2 then collected participants' attitudes and perceptions to shoulder padding, these were based on previous research relating to headgear [1], and included questions regarding shoulder padding usage, reasons for wearing and not wearing shoulder padding using open ended text box style questions, as well as participants' perceptions of how effective shoulder padding is with regards to injury prevention both generally using a 5-point Likert scale $(1=$ 'not at all', $5=$ 'a great deal') and specifically to certain injuries using a different 5-point Likert scale ( $1=$ 'very ineffective', $5=$ 'very effective'). Injuries were grouped by type based on previous rugby based consensus statements (Fuller et al., [6]). And are as follows (Cuts and Abrasions, Bruising, Sprain/Ligament damage, Nerve injury, Dislocations, Bone injury), examples of each were given on the survey. Section 3 then collected information regarding the participants' shoulder injury history to date so that shoulder pad usage and attitudes could be linked with shoulder injury experience as well as add to epidemiological data. Participants were asked to recall their career injury history and categorise them into the previously mentioned categories, no other injury history information was taken due to the possibility for systematic error. The questionnaire included both closed and open questions. This mixed methods design allowed for descriptive and interpretive information to be obtained.

\section{Survey Deployment}

Rugby players aged $13^{+}$of any gender and skill level were targeted during the deployment of the questionnaire, parental consent (under 18s) was taken. The questionnaire was distributed to respondents between May and July 2018. The questionnaire was publicised through various social media platforms including directly through World Rugby's twitter handle. Various English rugby clubs were also approached, and the survey link was sent to its members. The country in which the respondents resided was not controlled and was only available in English.

\section{Data Analysis}

Quantitative data was inputted into SPSS (version 25) and descriptive statistics were produced in order to examine demographics, shoulder pad usage, and shoulder injury history. Any incomplete data was disregarded. After parametric checks, ordinal regression analysis was performed to identify significant predictors for two dependent variables, (the perceived effectiveness of padding and specific injury history i.e. dislocations, bruising). Open ended survey responses (reasons for wearing and not wearing shoulder padding) were examined using a thematic approach, as used by Braun and Clark [2] Eight higher order themes were identified for the open ended questions using an inductive approach. Raw data was coded into groups by the principal researcher, this process was then discussed with the research team and a consensus made to ensure trustworthiness of the data. Descriptive statistics for these themes were then produced in order to examine the responses. 


\section{Results}

\section{Basic Characteristics}

At total of 616 responses were collected from the survey, giving a wide demographic of rugby players (Table 1).

\section{Shoulder Pad Use}

There are $66.1 \%(n=407)$ of players worn shoulder padding at some point. Among them, 9.9\% $(n=61)$ always wore shoulder padding, $17.7 \%(n=109)$ only wore shoulder padding during matches, $13.1 \%(n=81)$ wore shoulder padding, but only because of an injury and $25.3 \%(n=156)$ wore shoulder padding regularly in the past but at present

Table 1 Demographic information of players surveyed

\begin{tabular}{lc}
\hline Characteristic & $\begin{array}{c}\text { Responses } \\
\text { (number }(\%))\end{array}$ \\
\hline Sex & \\
Male & $574(93.2)$ \\
Female & $40(6.5)$ \\
Prefer not to say & $2(0.3)$ \\
Age & \\
13-17 & $33(5.4)$ \\
18-23 & $217(35.2)$ \\
24-29 & $146(23.7)$ \\
30-35 & $82(13.3)$ \\
Above 36 & $138(22.4)$ \\
Playing experience & \\
Under a year & $10(1.6)$ \\
1-2 years & $25(4.1)$ \\
3-5 years & $87(14.1)$ \\
6-9 years & $104(16.9)$ \\
10+years & $390(63.3)$ \\
Highest playing level & \\
School & $10(1.6)$ \\
Junior club & $28(4.5)$ \\
Junior county & $10(1.6)$ \\
Academy & $18(2.9)$ \\
University & $112(18.2)$ \\
Senior social & $115(18.7)$ \\
Senior amateur & $255(41.4)$ \\
Semi-professional & $57(9.3)$ \\
Professional & $10(1.6)$ \\
Playing position & $211(34.3)$ \\
Bront row forwards & \\
Backs & \\
\hline
\end{tabular}

did not. There are $61 \%(n=111)$ of front row forwards, $61 \%(n=136)$ of back five forwards and $74 \%(n=129)$ of backs who had worn shoulder padding at some point.

\section{Attitudes Towards Effectiveness of Shoulder Padding}

The median perception of the effectiveness (Likert scale 1-5) of padding was 2 (Inter Quartile Range $(I Q R)=2-3)$. When player's behaviours were factored in, the results were, those that always wore shoulder padding $($ Median $=3, \mathrm{IQR}=3$ ), only wore shoulder padding in matches (Median $=3, \mathrm{IQR}=2-3$ ), wore shoulder padding, but only because of an injury (Median $=2, I Q R=2$ ), wore shoulder padding regularly in the past but at present did not $($ Median $=3, \mathrm{IQR}=2-3)$, and had never worn shoulder padding (Median $=3, \mathrm{IQR}=2-3$ ). Based on the regression model, those that always wore shoulder padding $\left(\Delta R^{2}=0.19\right.$, $B=2.25, S E=0.28, C I 1.70-2.80, P=0)$, only wore shoulder padding in matches $\left(\Delta R^{2}=0.19, B=1.81, S E=0.23\right.$, CI 1.36-2.23, $P=0$ ), and those that wore shoulder padding, but only because of an injury $\left(\Delta R^{2}=0.19, B=0.59\right.$, $S E=0.24, C I 0.12-1.06, P=0.014)$ had a positive association with perceived effectiveness. Gender $(P=0.245)$, playing position $(P=0.109)$ and playing level $(P=0.540)$ had no significant association with the perceived effectiveness of padding. However, when taking into account age, the group 24-29 had an inverse association with shoulder padding effectiveness $\left(\Delta R^{2}=0.03, B=-0.53, S E=0.22, C I-0.95\right.$ to $-0.10, P=0.015)$. Playing experience groups $1-2$ years $\left(\Delta R^{2}=0.03, B=0.8, S E=0.04, C I 0.07-1.53, P=0.032\right)$, 3-5 years $\left(\Delta R^{2}=0.03, B=0.70, S E=0.22, C I 0.26-1.13\right.$, $P=0.002)$ and 6-9 years $\left(\Delta R^{2}=0.03, B=0.41, S E=0.2\right.$, $C I 0.02-0.80, P=0$ ) had a positive association with padding effectiveness.

Respondents considered shoulder padding to be either effective (37.1\%) or very effective (21.9\%) at preventing Cuts and Abrasions; 50.3\% considered it to be effective and 9.7\% very effective at preventing Bruising; $17.4 \%$ of respondents considered it either effective or very effective at preventing Sprain/Ligament damage, as well as $10.6 \%$ for Dislocation and $21.5 \%$ for Bone injury (Fig. 1). Based on the regression model, whether a player had received a specific injury had no association with their perceived effectiveness of shoulder padding except for a Bone injury. A positive association was found between perceived effectiveness of shoulder padding preventing bone injury $\left(\Delta R^{2}=0.01, B=0.50, S E=0.21, C I\right.$ 0.095 to $-0.9, P=0.016$ ) and whether a player had received a Bone injury as a result of playing rugby. This indicating that players who had received a Bone injury thought shoulder padding was more effective at preventing this injury than player who had not received a Bone injury. 
Fig. 1 The perceived effectiveness of padding for specific injuries
60

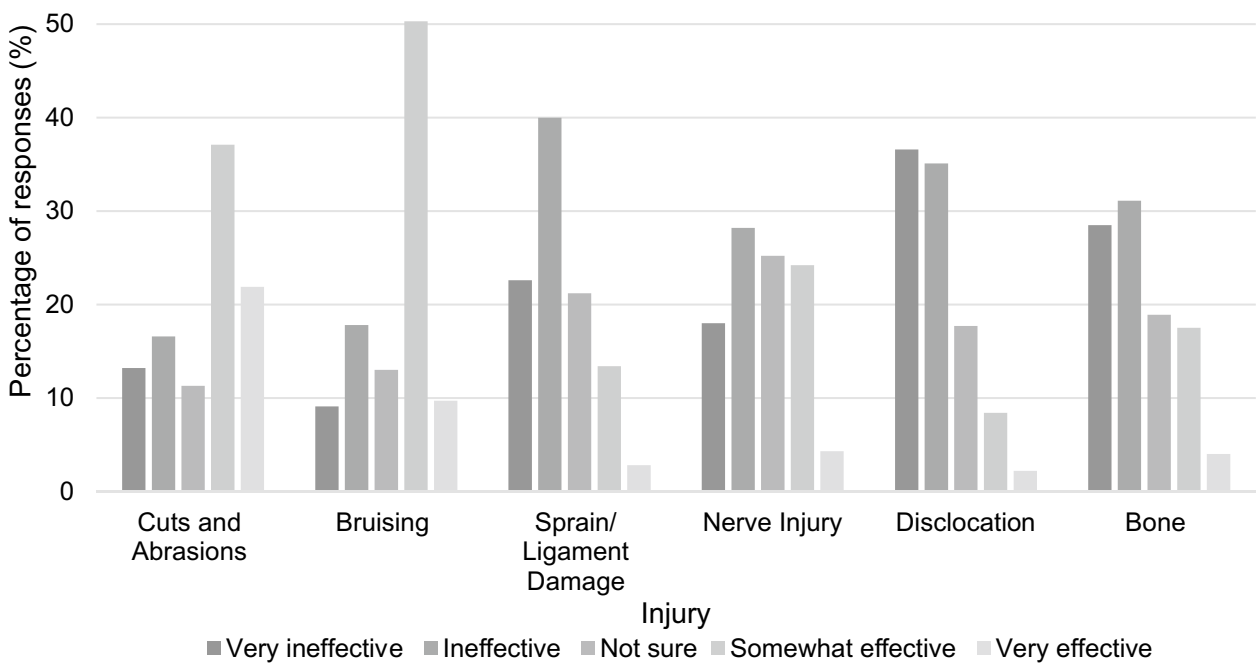

\section{Attitudes of Players Who Wear Shoulder Padding}

Eight themes were identified when considering players who had worn shoulder padding at some point (Table 2). Of these players, $62.6 \%$ of responses indicated wearing shoulder padding as a form of protection or injury prevention with $19.2 \%$ of these being to protect from a reoccurring injury; $15.8 \%$ of responses implied rugby players wore shoulder padding to feel more confident, mainly in the tackle situation; and $9.3 \%$ of responses indicated wearing shoulder padding for comfort in impacts rather than as a form of protection.

\section{Attitudes of Players Who do not Wear Shoulder Padding}

Eight themes were identified when considering players who did not wear or chosen to stop wearing shoulder padding (Table 3). Among them, $38.6 \%$ of responses indicated wearing shoulder padding was not needed, with $21.3 \%$ of responses indicating shoulder padding was uncomfortable; and $16.8 \%$ of responses indicated rugby players did not feel padding had added protective benefits.

\section{Shoulder Injury Data}

There are $72.8 \%(n=447)$ of players who reported a shoulder related rugby injury. Of those that reported having a shoulder related injury, $35.8 \%(n=160)$ reported experiencing a Cut or Abrasion injury, 55.5\% $(n=248)$ a Bruising injury, $57.5 \%(n=257)$ a Sprain/Ligament related injury, $33.1 \%(n=148)$ a Nerve related injury, $18.1 \%(n=81)$ a Dislocation and $20.0 \%(n=89)$ a Bone related injury. Using the regression model, players use of padding could be used to predict what specific injuries they had sustained, the category 'I've worn shoulder padding, but only because of an injury' was discounted. Players that always wore shoulder padding $\left(\Delta R^{2}=0.033, B=0.63, S E=0.30, C I 0.05-1.21\right.$, $P=0.034)$, only wore shoulder padding in matches $\left(\Delta R^{2}=0.033, B=0.48, S E=0.25, C I 0-0.96, P=0.049\right)$, and have worn padding regularly in the past but at present do not $\left(\Delta R^{2}=0.033, B=0.46, S E=0.22, C I 0.03-0.89, P=0.038\right)$, had a positive association with having sustained a Bruising injury. Players that only wore shoulder padding in matches $\left(\Delta R^{2}=0.04, B=0.83, S E=0.29, C I 0.27-1.39, P=0.003\right)$, and have worn padding regularly in the past but at present do not $\left(\Delta R^{2}=0.04, B=0.78, S E=0.26, C I 0.26-1.29\right.$, $P=0.003$ ), had a positive association with having sustained a Sprain/Ligament injury. Players that only wore shoulder padding in matches $\left(\Delta R^{2}=0.07, B=0.99, S E=0.34, C I\right.$ $0.32-1.67, P=0.004)$, had a positive association with Bone injury. Figure 2 displays specific shoulder injury history as a function of shoulder padding usage. Backs sustained less shoulder injuries $(66 \%)$, when compared to front row forwards (79\%) and back five forwards (74\%). 89\% of the front row that always wore padding had sustained an injury compared with the $66 \%$ that had never worn padding. However, $50 \%$ of the backs that always wore shoulder padding had sustained a shoulder injury, this was the same for the backs that never wore padding $(50 \%)$.

\section{Discussion}

\section{Shoulder Padding}

The regression model showed increased perceived effectiveness of padding with increased use. Both players who always wore padding, only wore padding in matches and those that 
Table 2 Reason themes for wearing shoulder padding (listed from most to least common)

\begin{tabular}{|c|c|}
\hline Higher order themes $(n=386)$ & Example responses \\
\hline Injury prevention and padding $(43.5 \%)$ & $\begin{array}{l}\text { Protection } \\
\text { Protect from minor shoulder injury } \\
\text { Degree of protection offered to shoulder and collar bone in contact } \\
\text { Protect against soft tissue injury }\end{array}$ \\
\hline Protection from reoccurring injury $(19.2 \%)$ & $\begin{array}{l}\text { To protect my shoulder whilst it wasn't } 100 \% \\
\text { Returning from an injured shoulder } \\
\text { To reduce impact on shoulders following an injury } \\
\text { Damaged my ac joint and padding it was the only way I could tackle with the least amount of } \\
\text { discomfort }\end{array}$ \\
\hline Confidence $(15.8 \%)$ & $\begin{array}{l}\text { When I first played contact rugby, it gave me greater confidence when making a tackle } \\
\text { Confidence in the tackle area } \\
\text { Purely confidence. I don't believe it helps, other than my mind } \\
\text { Feel more secure } \\
\text { It makes me feel more confident about making tackles in matches }\end{array}$ \\
\hline Comfort in impacts $(9.3 \%)$ & $\begin{array}{l}\text { Just gives a little bit of extra comfort in the pack for tackling and scrums } \\
\text { Less sore shoulders after scrum } \\
\text { Gives me more comfort when making tackles on oppositions bony parts }\end{array}$ \\
\hline $\begin{array}{l}\text { Recommendation from coaches, friends or } \\
\text { parents }(7.3 \%)\end{array}$ & $\begin{array}{l}\text { When I was younger I wore it for shoulder protection mainly on the insistence of my Mum } \\
\text { Was recommended by the coach } \\
\text { It was popular to wear them }\end{array}$ \\
\hline Habit $(1.8 \%)$ & $\begin{array}{l}\text { It feels part of my gear, same as gumshield, shorts etc } \\
\text { Was given to me for free, got used to wearing it and then didn't like the feel of playing without it }\end{array}$ \\
\hline To change own physical appearance (1.6\%) & $\begin{array}{l}\text { Being smaller than everyone else } \\
\text { Due to my size frame shoulder pads helped make me feel bigger, it had a bit of placebo effect }\end{array}$ \\
\hline To try it out $(1.6 \%)$ & No specific reason, a friend gave it to me and I decided to try it out \\
\hline
\end{tabular}

wore shoulder padding, but only because of an injury had a positive association with the perceived effectiveness of shoulder padding. When exploring this further, both the variables age and playing experience influenced perceived effectiveness of shoulder padding. The age group 24-29 had an inverse association with perceived effectiveness and playing experience groups 1-2 years, 3-5 years and 6-9 years had a positive association. It would be very exploratory to state a reason for this, however it is suggested male rugby players are at their peak muscle mass in the 24-29 age group, therefore may feel they do not need shoulder padding as a result [8]. When taking demographic information into account, no other group had a significant positive or negative association with perceived shoulder padding effectiveness. Whilst there seems to be a good awareness into the limitations shoulder padding has at preventing injury, further education should be directed to all playing groups in order to reinforce player knowledge.

There are $59 \%$ of respondents considering shoulder padding to be either effective or very effective at preventing Cuts and Abrasions and $60 \%$ of respondents considering shoulder padding to be either effective or very effective at preventing Bruising injury, complimenting previous research into padded headgear, finding $55 \%$ of respondents to consider headgear to be effective at preventing minor injuries [1]. Shoulder padding's ability to reduce the risk of superficial injuries like Cuts and Bruising must be measured in order to justify rugby players' perceptions of padding. There are $10.6 \%$ considering shoulder padding to be either effective or very effective at preventing Dislocations, as well as $21.5 \%$ considering shoulder padding to be either effective or very effective at preventing bone injury. However, this is yet to be proven or quantified, this also does not align with World Rugby's views. Further education as well as responsible marketing from manufacturers and governing bodies should be considered to ensure fewer rugby players view shoulder padding as an effective tool at preventing severe injuries.

The primary reasons for wearing shoulder padding were as a means of injury prevention $(43.5 \%)$ or to protect from reoccurring injury (19.2\%). This was expected due to how shoulder padding is commercially branded and its proven impact force attenuating abilities [10]. There are $15.8 \%$ of players wore shoulder padding to increase confidence, mainly in the tackle. The outweighing association that players use shoulder padding as a means of injury prevention 
Table 3 Reasons for not wearing shoulder padding

\begin{tabular}{|c|c|}
\hline Higher order themes $(n=352)$ & Example responses \\
\hline They are not required $(38.6 \%)$ & $\begin{array}{l}\text { I stopped wearing it as I did not need them to absorb impacts anymore } \\
\text { Just never bothered with it } \\
\text { I do not see the need for shoulder padding, I've never hurt my shoulders before } \\
\text { Injury healed so no longer required shoulder pad protection }\end{array}$ \\
\hline Discomfort (21.3\%) & $\begin{array}{l}\text { I stopped as it was uncomfortable and I tended to overheat } \\
\text { Can get too hot wearing them and sometimes uncomfortable } \\
\text { I get too hot wearing them otherwise I would probably wear them all the time } \\
\text { I feel claustrophobic in them at times and get too hot }\end{array}$ \\
\hline Do not offer protection (16.8\%) & $\begin{array}{l}\text { I am unaware of the difference it could make to my safety or skills } \\
\text { Did not seem to help with anything as so thin } \\
\text { No added benefits to protection }\end{array}$ \\
\hline Restricts movement $(6.3 \%)$ & $\begin{array}{l}\text { It adds bulk, makes it harder to manoeuvre } \\
\text { Movement limiting } \\
\text { My movement felt restricted with the pads, and I wanted full movement to avoid injury }\end{array}$ \\
\hline Cost and Availability (6.3\%) & $\begin{array}{l}\text { It seems unnecessary and is an expense I cannot really afford } \\
\text { Too costly to replace }\end{array}$ \\
\hline Impacts the game negatively (4\%) & $\begin{array}{l}\text { I enjoy the hard-hitting nature of the game which I feel would lack with pads } \\
\text { Not wearing shoulder padding encourages a correct technique in tackle/contact situations and obser- } \\
\text { vation of the laws of the game. Wearing padding too easily encourages reckless and undisciplined } \\
\text { hits from bad angles with greater force } \\
\text { Enjoying the tackle more without them }\end{array}$ \\
\hline Stigma $(3.7 \%)$ & $\begin{array}{l}\text { Not the manly thing to do } \\
\text { It's for girls } \\
\text { There is a perception of people who wear padding being 'soft' }\end{array}$ \\
\hline False sense of security $(3.1 \%)$ & $\begin{array}{l}\text { It gives a false sense of security, if you're going to break your bones, you're going to break your bones } \\
\text { Disagree with it. I believe it gave a false belief to those who did }\end{array}$ \\
\hline
\end{tabular}

suggests this increased confidence stems from a decreased worry about getting injured. This result is similar to a study by Barnes et al. [1], on protective rugby headgear where $13 \%$ of responses related to increased confidence as a motivation for its use. It is however, important to note World Rugby does not view shoulder padding as a form of protective equipment and has set impact attenuating abilities to a maximum limit, with the view of not over protecting players and changing their on pitch behaviours [20]. It has however been suggested that some players can become overly reckless when wearing protective equipment [9], further backed up by $3.1 \%$ of reasons for not wearing shoulder padding being related to the feeling of a false sense of security.

The primary reason for not wearing padding was that shoulder pads were not needed in rugby (38.6\%). Previous research suggests the physical nature of the game leads to players adopting a mind-set where extra padding is not needed [3]. Discomfort (21.3\%) and the feeling of restricted movement $(6.3 \%)$ were also key reasons for not wearing padding. Similar to research into padded headgear in rugby, which also found discomfort and heat regulation issues to be the primary reasons for not wearing padded headgear
[4]. In the survey, $16.8 \%$ of respondents felt shoulder padding offered no extra protection. Further research into what injuries shoulder padding may reduce the risk of is needed, followed by education of these findings to rugby players. Manufacturers should consider the factors of discomfort and restricted movement while also acknowledging World Rugby regulations when designing future products.

\section{Shoulder Injury}

Sprain/Ligament damage (57.5\%) and Bruising injuries (55.5\%) were the most prevalent. Previous research reports a lower frequency of Bruising injuries (12\%-17\% [11, 16]). Possibly due to the injury definition used in both studies ( 24 + hours' time loss) which would lead to the underreporting of a Bruise that may not be of the severity to cause time loss or require medical attention. As well as this, it is possible players in the current study were more likely to respond to the survey if they had had a shoulder injury. Comparing this data to the data mentioned must be done with caution due to the significant differences in approaches taken. The large prevalence of reported Bruising injuries to the shoulder 


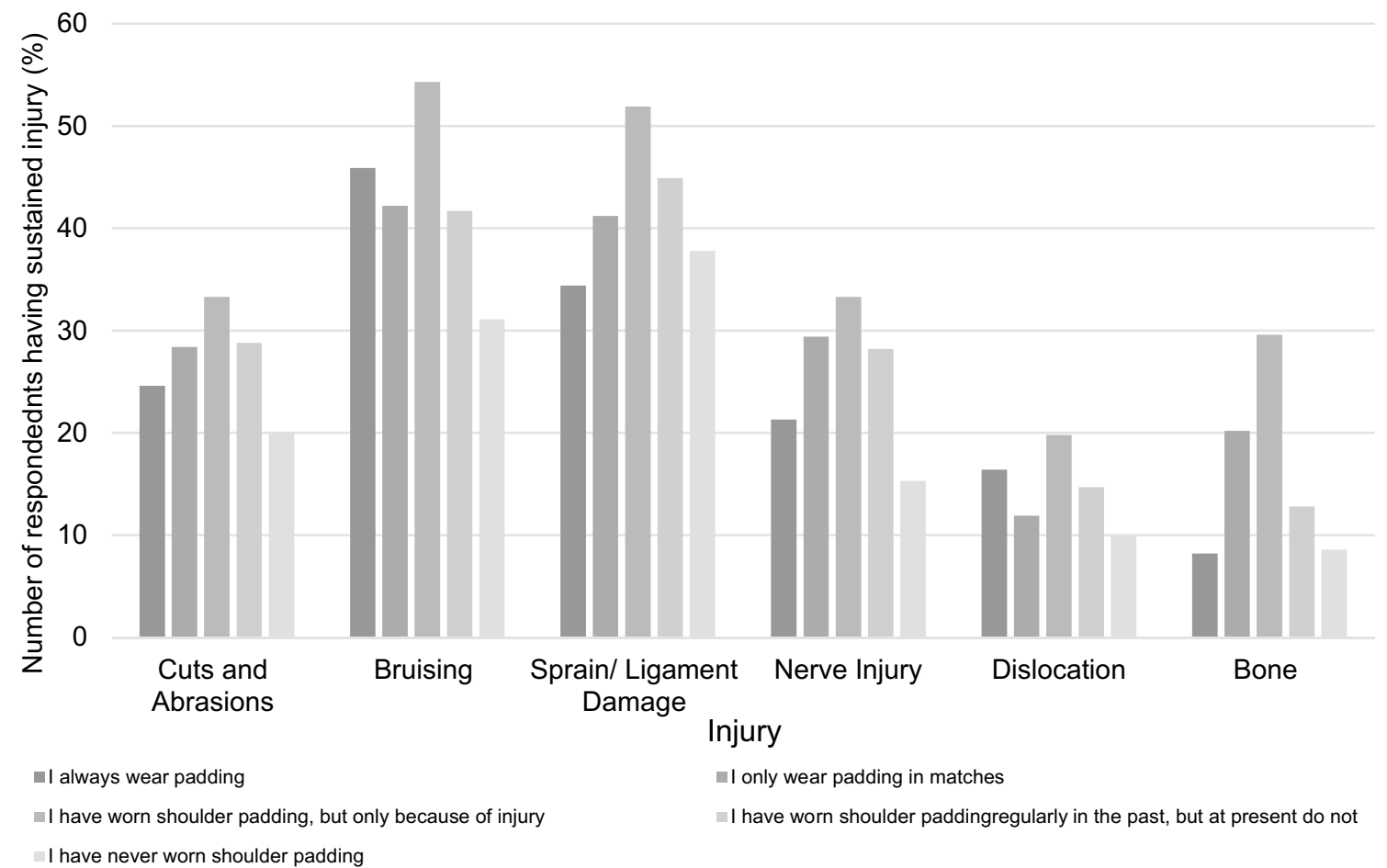

Fig. 2 Specific shoulder injury history as a function of shoulder pad usage

does suggest shoulder padding's ability to decrease the risk of a Bruise should be explored. This also the case with Cut and Abrasion injuries, $35.8 \%$ of respondents had sustained a Cut or Abrasion as a result of playing rugby. No published research reports Cuts, Lacerations, or Abrasions specifically to the shoulder region. With regards to less severe injuries, players that always wore padding had sustained more Cuts and Abrasions (24.6\%) and Bruising injuries (45.9\%) than that of players that had never worn padding $(20.1 \%, 31.1 \%)$. Players that had never worn padding felt they did not see the need to wear it, potentially because they did not need the added protection (i.e. increased muscle mass), therefore potentially explaining the larger reporting of less severe injuries in players that always wear padding. Coupled with this, some players that had never worn padding did so out of stigma. The stigma of wearing padding may also have led to the under reporting of less severe injuries like Cuts, Abrasions and Bruising.

\section{Limitations}

Limitations stem from the method of data collection, recall bias may have been an issue due to the self-reporting style of data collection, enhanced when asking participants about their non-severe injury history beyond a year [18]. There is mixed findings on the validity of self-reporting injury data in this way $[12,15,17]$, future studies should use injury data reported by medical professionals. The varied demographic of respondents would have reduced selection bias, however $72.8 \%$ of respondents had had a shoulder injury, suggesting that individuals with previous shoulder injuries were more likely to respond to the study. Due to the data collection procedures of the study the severity of reported injuries was not recorded, this should be explored in the future. Future studies should explore whether shoulder pad use affects actual playing behavior as well as shoulder injury occurrence. There was limited heterogeneity in gender and playing level, with only $6.5 \%$ of respondents being female and $10.9 \%$ semi-professional or professional, this could reduce the variability in the results. Finally, the study did not account for the nationality or region of the participants, attitudes can differ by region limiting the ability of the study to know where the data generalises to.

\section{Conclusions}

The primary reason for wearing shoulder padding was as a means of injury prevention. Research should focus on quantifying the injury preventive capabilities of shoulder padding. Bruising, Cuts and Abrasion injuries to the shoulder are prevalent presenting new findings that these injuries are underreported. 
Supplementary Information The online version contains supplementary material available at https://doi.org/10.1007/s42978-021-00140-2.

Funding This project is funded by World Rugby and the Engineering and Physical Sciences Research Council (EPSRC).

Availability of Data and Material Raw data available on request from principal author.

Code Availability Not applicable.

\section{Declarations}

Conflict of Interest The authors declare no conflict of interest. The funding sponsors had no role in the design of the study; in the collection, analyses, or interpretation of data; in the writing of the manuscript, and in the decision to publish the results.

Ethical Approval The University of Sheffield ethics board gave ethical approval prior to the project, participants gave informed consent before completing the survey.

Open Access This article is licensed under a Creative Commons Attribution 4.0 International License, which permits use, sharing, adaptation, distribution and reproduction in any medium or format, as long as you give appropriate credit to the original author(s) and the source, provide a link to the Creative Commons licence, and indicate if changes were made. The images or other third party material in this article are included in the article's Creative Commons licence, unless indicated otherwise in a credit line to the material. If material is not included in the article's Creative Commons licence and your intended use is not permitted by statutory regulation or exceeds the permitted use, you will need to obtain permission directly from the copyright holder. To view a copy of this licence, visit http://creativecommons.org/licenses/by/4.0/.

\section{References}

1. Barnes A, Rumbold JL, Olusoga P. Attitudes towards protective headgear in UK rugby union players. BMJ Open SEM. 2017;3(1):e000255.

2. Braun V, Clarke V. Using thematic analysis in psychology. Qual Res Psychol. 2006;3(2):77. https://doi.org/10.1191/1478088706 qp063oa.

3. Comstock RD, Fields SK, Knox CL. Protective equipment use among female rugby players. CJSM. 2005;15(4):241-5. https:// doi.org/10.1097/01.jsm.0000171288.37293.54.

4. Finch CF, McIntosh AS, McCrory P. What do under 15 year old schoolboy rugby union players think about protective headgear? Br J Sports Med. 2001;35(2):89-94.

5. Fuller CW, Brooks JHM, Cancea RJ, Hall J, Kemp SPT. Contact events in rugby union and their propensity to cause injury. $\mathrm{Br}$ J Sports Med. 2007;41(12):862-7. https://doi.org/10.1136/bjsm. 2007.037499.
6. Fuller CW, Molloy MG, Bagate C, Bahr R, Brooks JHM, Donson H, Kemp SPT, McCrory P, McIntosh AS, Meeuwisse WH, Quarrie KL, Raftery M, Wiley P. Consensus statement on injury definitions and data collection procedures for studies of injuries in rugby union. Br J Sports Med. 2007;41(5):328-31. https://doi. org/10.1136/bjsm.2006.033282.

7. Fuller CW, Taylor A, Kemp SPT, Raftery M. Rugby World Cup 2015: World Rugby injury surveillance study. Br J Sports Med. 2017;51(1):51-7. https://doi.org/10.1136/bjsports-2016-096275.

8. Geeson-Brown T, Jones B, Till K, Chantler S, Deighton K. Body composition differences by age and playing standard in male rugby union and rugby league: a systematic review and metaanalysis. J Sports Sci. 2020;38(19):2161-76. https://doi.org/10. 1080/02640414.2020.1775990.

9. Hagel B, Meeuwisse W. Risk compensation: a "side effect" of sport injury prevention? CJSM. 2004;14(4):193-6.

10. Harris DA, Spears IR. The effect of rugby shoulder padding on peak impact force attenuation. Br J Sports Med. 2010;44(3):2003. https://doi.org/10.1136/bjsm.2008.047449.

11. Headey J, Brooks JHM, Kemp SPT. The epidemiology of shoulder injuries in English professional rugby union. Am J Sports Med. 2007;35(9):1537-43. https://doi.org/10.1177/0363546507300691.

12. Kucera KL, Marshall SW, Bell DR, DiStefano MJ, Goerger CP, Oyama S. Validity of soccer injury data from the National Collegiate Athletic Association's injury surveillance system. J Athl Train. 2011;46(5):489-99. https://doi.org/10.4085/1062-605046.5.489.

13. Marshall SW, Waller AE, Dick RW, Pugh CB, Loomis DP, Chalmers DJ. An ecologic study of protective equipment and injury in two contact sports. Int J Epidemiol. 2002;31(3):587-92.

14. Nicholl JP, Coleman P, Williams BT. The epidemiology of sports and exercise related injury in the United Kingdom. Br J Sports Med. 1995;29(4):232-8. https://doi.org/10.1136/bjsm.29.4.232.

15. Schuh-Renner A, Canham-Chervak M, Grier TL, Jones BH. Accuracy of self-reported injuries compared to medical record data. Musculoskelet Sci Pract. 2019;39:39-44. https://doi.org/10. 1016/j.msksp.2018.11.007.

16. Usman J, McIntosh AS, Quarrie K, Targett S. Shoulder injuries in elite rugby union football matches: epidemiology and mechanisms. J Sci Med Sport. 2015;18(5):529-33. https://doi.org/10. 1016/j.jsams.2014.07.020.

17. Valuri G, Stevenson M, Finch C, Hamer P, Elliott B. The validity of a four week self-recall of sports injuries. Inj Prev. 2005;11(3):135-7. https://doi.org/10.1136/ip.2003.004820.

18. Walter SD. Recall bias in epidemiologic studies. J Clin Epidemiol. 1990;43(12):1431-2. https://doi.org/10.1016/0895-4356(90) 90113-4.

19. World Rugby. Regulation 12. 2015. http://playerwelfare.world rugby.org/reg12. Accessed 29 July 2021.

20. World Rugby. Body padding performance specification. 2021. https://www.world.rugby/the-game/player-welfare/equipment/ specifications/body-padding. Accessed 29 July 2021.

21. Yeomans C, Kenny IC, Cahalan R, Warrington GD, Harrison AJ, Hayes K, Lyons M, Campbell MJ, Comyns TM. The incidence of injury in amateur male rugby union: a systematic review and meta-analysis. Sports Med. 2018;48(4):837-48. https://doi.org/ 10.1007/s40279-017-0838-4. 